\title{
Measurement of relative humidity dependent light scattering of aerosols
}

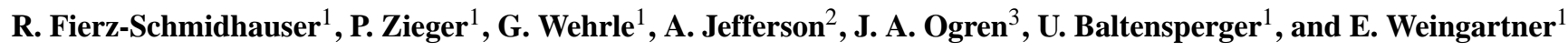 \\ ${ }^{1}$ Laboratory of Atmospheric Chemistry, Paul Scherrer Institut, Villigen, Switzerland \\ ${ }^{2}$ CIRES, University of Colorado, Boulder, 80305, Colorado, USA \\ ${ }^{3}$ National Oceanic and Atmospheric Administration (NOAA), Boulder, 80305, Colorado, USA
}

Received: 31 August 2009 - Published in Atmos. Meas. Tech. Discuss.: 15 September 2009

Revised: 18 December 2009 - Accepted: 6 January 2010 - Published: 21 January 2010

\begin{abstract}
Relative humidity (RH) influences the water content of aerosol particles and therefore has an important impact on the particles' ability to scatter visible light. The RH dependence of the particle light scattering coefficient $\left(\sigma_{\mathrm{sp}}\right)$ is therefore an important measure for climate forcing calculations. We built a humidification system for a nephelometer which allows the measurement of $\sigma_{\mathrm{sp}}$ at a defined $\mathrm{RH}$ in the range of $40-90 \%$. This RH conditioner consists of a humidifier followed by a dryer, which enables us to measure the hysteresis behavior of deliquescent aerosol particles.

In this paper we present the set-up of a new humidified nephelometer, a detailed characterization with well defined laboratory generated aerosols, and a first application in the field by comparing our instrument to another humidified nephelometer.

Monodisperse ammonium sulfate and sodium chloride particles were measured at four different dry particle sizes. Agreement between measurement and prediction based on Mie theory was found for both $\sigma_{\mathrm{sp}}$ and $f(\mathrm{RH})=\sigma_{\mathrm{sp}}(\mathrm{RH}) / \sigma_{\mathrm{sp}}($ dry $)$ within the range of uncertainty. The two humidified nephelometers measuring at a rural site in the Black Forest (Germany) often detected different $f(\mathrm{RH})$, probably caused by the aerosol hysteresis behavior: when the aerosol was metastable, therefore was scattering more light, only one instrument detected the higher $f(\mathrm{RH})$.
\end{abstract}

\section{Introduction}

Atmospheric aerosols influence the Earth's radiation budget both directly and indirectly. The change in the Earth's radiative balance due to aerosol light scattering and absorption

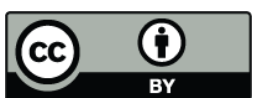

Correspondence to: E. Weingartner (ernest.weingartner@psi.ch) is called the direct aerosol effect. The radiative forcing can be negative or positive, depending on the chemical and microphysical properties of the involved aerosols and the Earth's surface albedo. The current global anthropogenic impact of the direct aerosol effect is estimated to be -0.5 $( \pm 0.4) \mathrm{Wm}^{-2}$, compared to the total anthropogenic radiative forcing of $+1.6(+0.6$ to +2.4$) \mathrm{Wm}^{-2}$ (IPCC, 2007). The total aerosol forcing uncertainty is substantially larger than that of greenhouse gases ( $+0.8 /-1.5$ vs. $\pm 0.27 \mathrm{Wm}^{-2}$ ) (Ramanathan et al., 2001; IPCC, 2007).

In this paper we will focus on the aerosol light scattering coefficient $\sigma_{\mathrm{sp}}$ and how it is influenced by the relative humidity $(\mathrm{RH})$ in the atmosphere. Wet aerosol particles are larger than their dry equivalents, therefore they scatter more light, which has a direct influence on the radiative forcing (White and Roberts, 1977; Tang et al., 1981; Sloane, 1984). However, the water content of the air, expressed in RH, does not always determine alone if a chemically defined aerosol particle is liquid or solid. For deliquescent aerosols, which can exist in two phases at the same RH, known as hysteresis (Orr Jr. et al., 1958), the RH history determines the aggregate state. Pure deliquescent aerosols undergo a sudden phase transition from solid to liquid in response to increasing RH. This phase transition occurs at a defined RH, called deliquescence relative humidity (DRH). Once the RH is above the DRH and the particle is liquid, decreasing RH does not make the particle recrystallize at the DRH. The particle solute concentration becomes supersaturated resulting in a metastable state until the RH decreases below a critical value at which recrystallization occurs. This RH is called efflorescence relative humidity (ERH). Mixed deliquescent aerosols can exhibit one or more phase changes as shown by Tang and Munkelwitz (1993). If the particles are not deliquescent but hygroscopic they grow or shrink monotonically with increasing or decreasing RH.

Published by Copernicus Publications on behalf of the European Geosciences Union. 
The exact knowledge of the DRH and ERH points is of great importance because they define - based on the RH history of an air parcel - which fraction of the atmospheric aerosol is present as purely liquid droplets. This fraction is scattering much more light than the fraction that is solid. Rood et al. (1989) found that metastable droplets existed more than $50 \%$ of the time in the atmosphere at three different locations in the USA. 5-15\% of the total particle scattering was attributed to metastable liquid water for RH values between 45 and $75 \%$.

The scattering coefficient, $\sigma_{\mathrm{sp}}$ can be measured by sampling ambient air into an integrating nephelometer. To ensure comparability between different GAW (Global Atmosphere Watch) stations, the World Meteorological Organization (WMO) recommends to measure $\sigma_{\mathrm{sp}}$ at $\mathrm{RH}$ below 40\% (WMO/GAW, 2003). Furthermore, WMO recommends to measure $\sigma_{\mathrm{sp}}$ as a function of RH. This measurement is needed to model the direct climate forcing by aerosol particles (Charlson et al., 1992; Schwartz, 1996) and is an important input parameter for models (Boucher and Anderson, 1995; Pilinis et al., 1995; Nessler et al., 2005). The information about the aggregation state improves the result of such model calculations.

Many ambient measurements of the light scattering enhancement factor $f(\mathrm{RH})=\sigma_{\mathrm{sp}}(\mathrm{RH}) / \sigma_{\mathrm{sp}}($ dry $)$ were performed during the last 40 years (Covert et al., 1972; Sheridan et al., 2001; Eldering et al., 2002; Kim et al., 2006; Haywood et al., 2008; Yan et al., 2009), but just a few included measurements on the metastability of aerosol particles (Rood et al., 1987; Carrico et al., 2003; Wang et al., 2007; Fierz-Schmidhauser et al., 2009).

Since data about the aggregate state (liquid or solid) of the aerosol are still scarce, we built a humidification system for a nephelometer that allows for the measurement of $\sigma_{\mathrm{sp}}$ at a defined humidity in the range of 40 to $90 \% \mathrm{RH}$. The system is able to measure the hygroscopic aerosol behavior and hysteresis effects and it can be continuously and remotely operated with very little maintenance. This paper discusses the experimental set-up of this instrument and a characterization with laboratory aerosols. In the second part we present a comparison of our instrument with another humidified nephelometer, which is, to our knowledge, the first direct comparison of two humidified nephelometers in the field.

\section{Experimental methods}

\subsection{Set-up of the humidified nephelometer}

We built a new humidification system for a three-wavelength $(450,550,700 \mathrm{~nm})$ total/backscatter integrating nephelometer (TSI Inc., Model 3563). Figure 1 shows the instrumental set-up. First, the aerosol enters a humidifier, which consists of a Gore-Tex ${ }^{\circledR}$ tube $($ diameter $=1 \mathrm{~cm}$, length $\approx 40 \mathrm{~cm}$ ), which is surrounded by a thin water layer in a heatable metal tube. Water temperature is controlled by

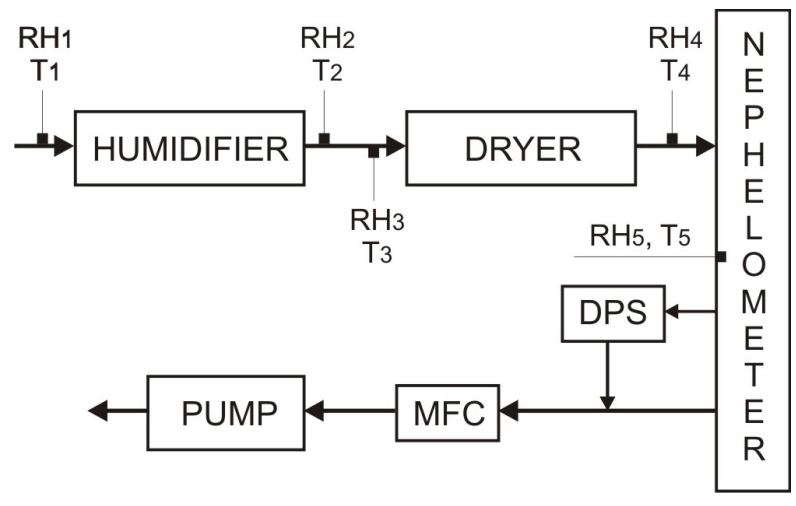

Fig. 1. Set-up of the humidified nephelometer, with five temperature ( $T$ ) and capacitive RH sensors, a dew point sensor (DPS) and a mass flow controller (MFC).

a PID- (proportional-integral-derivative) controller that uses the reading of an $\mathrm{RH}$ sensor $\left(\mathrm{RH}_{3}\right)$ as input. The humidifier is able to increase the RH to values of up to $95 \%$ at the applied flow rate of 16.6 liters per minute (lpm) (the maximum temperature of the aerosol at the exit of the humidifier is $<32^{\circ} \mathrm{C}$ to avoid volatilization losses). After passing through a $1 \mathrm{~m}$ metal tube the aerosol passes through a dryer, whose efficiency is monitored by another $\mathrm{RH}$ sensor $\left(\mathrm{RH}_{4}\right)$. The dryer consists of a single Nafion tube (Perma Pure LLC) with an inner diameter of $1.7 \mathrm{~cm}$ and a length of $1 \mathrm{~m}$. The aerosol flows through the inner part of the tube and can be dried by adjusting the flow and accordingly the pressure (200 mbar to ambient pressure) of an air stream around the Nafion tube (not shown in Fig. 1). At $16.6 \mathrm{lpm}$ the dryer is capable of reducing the RH from $85 \%$ to $55 \%$ at room temperature. Then, $\sigma_{\mathrm{sp}}$ of the aerosol particles is measured by the nephelometer at a monitored temperature and RH (temperature sensor $\mathrm{T}_{5}$, $\mathrm{RH}_{5}$ and dew point sensor, DPS).

A mass flow controller (MFC) regulates the air flow through the nephelometer. When the aerosol is humidified, the inlet volumetric flow will change slightly (e.g. by about $-1.5 \%$ at $85 \% \mathrm{RH})$. To avoid $\mathrm{RH}$ dependent variations of the inlet flow rate, we programmed the set point of the mass flow controller such that the volumetric flow at the inlet of the humidified nephelometer system is constant $(16.6 \mathrm{lpm})$, independently of how much water vapor is added and removed by the RH conditioning unit. We did not correct for changes in the aerosol concentration due to dilution (enrichment) effects by adding (removing) water vapor because this bias is small ( $<3 \%$ at $T=20^{\circ} \mathrm{C}$ and $1000 \mathrm{mbar}$ ).

Combined temperature and capacitive RH sensors (Rotronic HygroClipS, accuracy $\pm 0.3^{\circ} \mathrm{C}$ and $\pm 1.5 \% \mathrm{RH}$, according to the manufacturer) are used throughout the system to measure air temperature and RH, respectively (see Fig. 1). We moved the original RH and $T$ sensor in the nephelometer (described by TSI as the sample RH) to the nephelometer inlet (not shown in Fig. 1) and replaced it with a Rotronic 
HygroClipS $\left(\mathrm{RH}_{5}, \mathrm{~T}_{5}\right)$ which has a higher accuracy than the original sensor (the original sensor overestimates RH by up to $15 \% \mathrm{RH}$ at high $\mathrm{RH})$. However, the temperature measurement by the TSI sensor is necessary for the nephelometer calibration and was therefore kept in the system. In addition, a DPS (Edge Tech, Model 2000 Dewprime DF, accuracy $\pm 0.1{ }^{\circ} \mathrm{C}$ ) measures the dew point temperature in order to calculate (together with $\mathrm{T}_{5}$ ) the RH inside the nephelometer accurately. Due to the relatively long response time of DPS (up to several minutes) these RH readings were only applicable during stationary RH conditions. As an accurate $\mathrm{RH}$ measurement is crucial for such instruments, all RH sensors are calibrated every two months in the RH range of 11 to $98 \%$ by measuring $\mathrm{RH}$ over various saturated salt solutions ( $\left.\mathrm{LiCl}, \mathrm{NaCl},\left(\mathrm{NH}_{4}\right)_{2} \mathrm{SO}_{4}, \mathrm{~K}_{2} \mathrm{SO}_{4}\right)$. Within four subsequent calibrations the slopes between expected and measured $\mathrm{RH}$ range between 0.956 and 1.019 , with a $R^{2}>0.99$.

In the unmodified nephelometer, the heat of the halogen lamp $(75 \mathrm{~W})$ causes a temperature difference of about $4.5^{\circ} \mathrm{C}$ between the inlet and the sensing volume of the nephelometer $\left(\mathrm{T}_{5}-\mathrm{T}_{4}\right)$ at $16.6 \mathrm{lpm}$. Consequentially, the RH in the sensing volume decreases from e.g. $90 \% \mathrm{RH}$ to about $70 \% \mathrm{RH}$. In our set-up we reduced this temperature difference to less than $1{ }^{\circ} \mathrm{C}$ with the following modifications: An air-cooled infrared filter (KPF65, Filtrop AG with $>90 \%$ transmission for wavelengths between 420 and $760 \mathrm{~nm}$ ) was placed between the lamp and the sensing volume. On the outside of the sensing volume cooling fins enlarge the surface, where four additional blowers surround the nephelometer and adjust its temperature close to room temperature.

Aerosol passing through the system encounters the highest $\mathrm{RH}$ just before the dryer $\left(\mathrm{RH}_{3}\right)$. $\mathrm{RH}$ is then lowered by the dryer, and lowered further in the nephelometer because of the $\sim 1{ }^{\circ} \mathrm{C}$ temperature increase. As a consequence, substances that may exist in two phases deliquesce if their DRH is exceeded before the dryer. These particles will remain liquid even if the RH is subsequently lowered on the way to the nephelometer. Since we refer to this lower RH in the nephelometer in all our figures, the apparent deliquescence step change appears at a lower RH than the literature value. As an example for this phenomenon, Fig. 2 shows a measured humidogram of $f(\mathrm{RH})$ for sodium chloride, where the $\mathrm{x}$-axis represents the RH in the nephelometer and the color scale represents the $\mathrm{RH}$ at the most humid location $\left(\mathrm{RH}_{3}\right)$. The literature value for DRH of sodium chloride is $75.3 \%$ RH (at 298 K) (Tang and Munkelwitz, 1993). The measured phase transition occurs at $\mathrm{RH}_{3}=75 \%$, but appears at the lower sample RH of about $70 \%$ in the nephelometer. Due to the limited drying capability of the dryer, the ERH could not be determined during this experiment.

We define two different operating conditions for the humidified nephelometer: hydration and dehydration. Hydration is when the dryer is turned off and the RH between the entrance of the dryer and the entrance of the nephelometer is not changing within more than $3 \%$ (see Fig. A1a in the

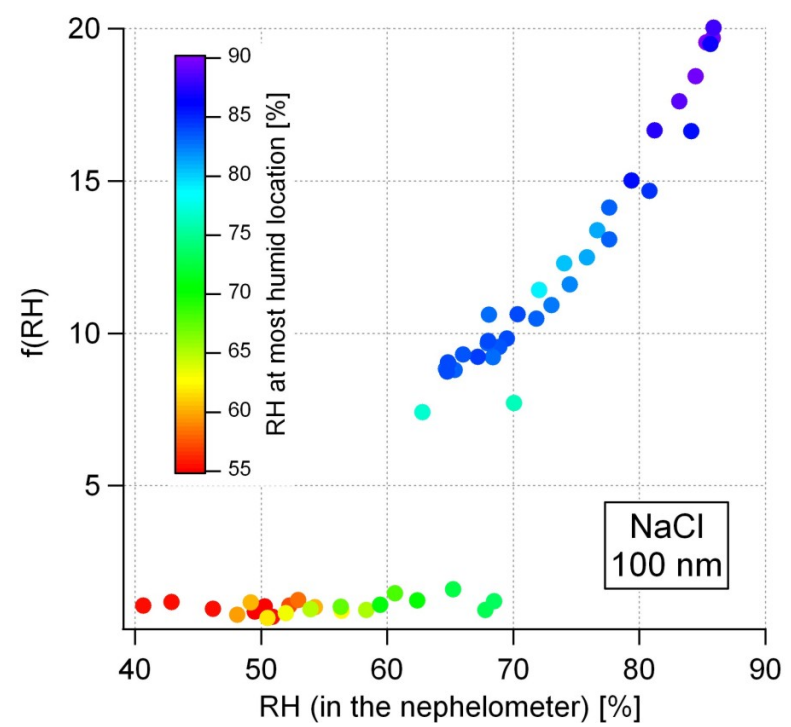

Fig. 2. $f(\mathrm{RH})$ vs. $\mathrm{RH}$ of sodium chloride particles with a dry diameter of $100 \mathrm{~nm}$, at $\lambda=550 \mathrm{~nm}$. The phase transition at deliquescence occurred at about $\mathrm{RH}=75 \%$ at the most humid location in the system $\left(\mathrm{RH}_{3}\right)$, as shown with the color scale.

Appendix). We define dehydration in a similar manner: after the humidifier $\left(\right.$ at $\left.\mathrm{RH}_{3}\right)$ the aerosol particles are exposed to $\mathrm{RH}>80 \%$. In the following, they encounter a lower $\mathrm{RH}$ in the dryer, which is now turned on (see Fig. A1b).

The residence time of the aerosol at high RH depends on the operating conditions. During hydration the aerosol experiences $\sim 3 \mathrm{~s}$ at high RH before entering the nephelometer while during dehydration this time is shortened to $\sim 1 \mathrm{~s}$.

\subsection{Laboratory measurements of monodisperse inorganic aerosol particles}

Well defined aerosols, ammonium sulfate $\left(\left(\mathrm{NH}_{4}\right)_{2} \mathrm{SO}_{4}\right)$ and sodium chloride $(\mathrm{NaCl})$, were generated by nebulizing the corresponding aqueous salt solutions (concentration $=10 \mathrm{~g} / \mathrm{l}$ ) with a nebulizer (model TSI 3076). The dried aerosol particles $(\mathrm{RH}<10 \%)$ were fed to a DMA (differential mobility analyzer) for selection of a specified particle electrical mobility (singly charged particles with diameter $D=100 \mathrm{~nm}$, $150 \mathrm{~nm}, 240 \mathrm{~nm}$ and $300 \mathrm{~nm}$ ). The quasi monodisperse aerosol $(0.3 \mathrm{lpm})$ exiting the DMA was mixed with filtered room air $(17.2 \mathrm{lpm})$, and the resulting air flow was split for a CPC (condensation particle counter, TSI 3010, $0.91 \mathrm{pm}$ ) and the humidified nephelometer (16.6 lpm). Between every RH cycle of the humidified nephelometer an SMPS (scanning mobility particle sizer) measured the polydisperse dry number size distribution entering the DMA in the diameter size range of $D=14$ to $791 \mathrm{~nm}$. With these data we calculated the size distribution of the quasi monodisperse aerosol at the entrance of the nephelometer, including the number of singly, doubly and triply charged particles. Even though multiply 
charged particles are considerably less numerous than the singly charged ones they can significantly contribute to light scattering due to their larger size. The percentage of doubly and triply charged particles in terms of numbers ranged from 9.5 to $24 \%$, and from 1.5 to $6 \%$, respectively. For the $100-\mathrm{nm}$ particles with $24 \%$ doubly charged particles and $6 \%$ triply charged particles the singly charged particles are only contributing about $10 \%$ to the total scattering and the triply charged particles contribute about $19 \%$ to the total scattering. For the 300-nm particles with $9.5 \%$ doubly charged particles and $1.5 \%$ triply charged particles the respective numbers are $32 \%$ and $38 \%$.

During the time that a RH cycle took place, the number concentration of the quasi monodisperse salts changed slightly (maximum $15 \%$ ). Therefore $\sigma_{\text {sp }}$ was normalized by the measured total particle number concentration.

For comparison with theoretical $\sigma_{\mathrm{sp}}$ values a model based on Mie theory was used. The particles were assumed to be spherical with a homogeneous composition. Assuming spherical particles is justified for this application, since the influence of non-sphericity on $\sigma_{\mathrm{sp}}$ is less than $\pm 5 \%$ for cubic salt particles smaller than $1 \mu \mathrm{m}$ (Chamaillard et al., 2006). The core Mie routine is based on the code of Bohren and Huffmann (2004). As inputs for the prediction the dry DMA size distribution, the complex refractive index and the RH in the nephelometer were used. The influence of the water uptake on the particle diameter was calculated by using the hygroscopic growth factors from Topping et al. (2005). For the wet refractive index a volume weighting between the refractive indices of water and the according salt was chosen.

The scattering coefficients were corrected for the truncation error according to Anderson and Ogren (1998), with the correction for particles with diameters smaller than $1 \mu \mathrm{m}$. Particle losses in the humidifier and dryer were determined with monodisperse aerosol and accounted for in the prediction of $\sigma_{\mathrm{sp}}$. At the standard flow of $16.6 \mathrm{lpm}$ the particle losses are 5, 3.5, 2.5 and $2.5 \%$ for $D=100,150,240$ and $300 \mathrm{~nm}$, respectively.

For both the measured and the theoretical scattering coefficients $\sigma_{\mathrm{sp}}$ we calculated the light scattering enhancement factor $f(\mathrm{RH})$ :

$$
f(\mathrm{RH})=\frac{\sigma_{\mathrm{sp}}(\mathrm{RH})}{\sigma_{\mathrm{sp}}(\mathrm{RH}=\mathrm{dry})} .
$$

The model output uncertainty of $\sigma_{\mathrm{sp}}$ and $f(\mathrm{RH})$ was determined by recalculating $\sigma_{\mathrm{sp}}$ with errors added to each input parameter $(\mathrm{RH}( \pm 2 \%), D( \pm 2 \mathrm{~nm})$, number concentration $N$ $( \pm 10 \%)$; the error of the complex refractive index was neglected). Resulting typical errors of $f(\mathrm{RH})$ are up to $\pm 50 \%$ for the $100-\mathrm{nm}$ size particles and $\pm 20 \%$ for the 300 -nm particles. These added errors will appear in the figures as the grey regions. The most dominant source of uncertainty for $\sigma_{\mathrm{sp}}$ is the number size distribution of the quasi monodisperse aerosol, whereas for $f(\mathrm{RH})$ the correct $\mathrm{RH}$ in the nephelometer is crucial.

\subsection{Field measurements}

To compare our humidified nephelometer (PSI humidified nephelometer, Paul Scherrer Institute) with the humidograph of DOE/ARM (US Department of Energy Atmospheric Radiation Measurements), we operated the two instruments in parallel for about one month (9 to 31 August 2007). The DOE/ARM humidograph consists of two integrating nephelometers (TSI Inc., model 3563) with a humidifier in between them (Carrico et al., 1998). $\sigma_{\mathrm{sp}}$ is measured by the first nephelometer at low-RH conditions and by the second at varying RH. No dryer is employed in this instrument (hydration mode only) and the residence time of the aerosol at high $\mathrm{RH}$ before entering the nephelometer is $\sim 0.2 \mathrm{~s}$. No infrared blocking and cooling system is used in the DOE/ARM system. However, the thermal gradient across this nephelometer is small. This gradient is about $1.0^{\circ} \mathrm{C}$ at low $\mathrm{RH}$ and about $-0.5^{\circ} \mathrm{C}$ at high $\mathrm{RH}$, meaning that the nephelometer interior is slightly cooler than the nephelometer inlet at high $\mathrm{RH}$ values. The humidifier ends at the inlet of the humidified nephelometer, so the nephelometer inlet is warm from the humidifier.

This instrument was running at the DOE/ARM Mobile Facility (AMF) in the context of the Convective and Orographically Induced Precipitation Study (COPS) field campaign in Heselbach (Black Forest, Germany) from March to December 2007 (Wulfmeyer et al., 2008).

During the comparison both systems got their samples from the $12-\mathrm{m}$ high community inlet of the AMF. The DOE/ARM system sampled with $30 \mathrm{lpm}$ volumetric flow rate whereas the PSI humidified nephelometer ran at a flow rate of $16.6 \mathrm{lpm}$. Upstream of the PSI humidified nephelometer the air stream passed through a $\mathrm{PM}_{10}$ impactor (selecting particles with an upper size cut (50\% removal efficiency) of an aerodynamic diameter of less than $10 \mu \mathrm{m}$ ) and for 10 days additionally through a $\mathrm{PM}_{1}$ cyclone. The tubes in front of the impactors were heated such that the RH of the air was below $35 \%$ during the size cut, whereas the temperature never exceeded $34^{\circ} \mathrm{C}$ to limit losses of semi-volatile species (Bergin et al., 1997; ten Brink et al., 2000). The DOE/ARM instrument changed between $\mathrm{PM}_{10}$ and $\mathrm{PM}_{1}$ every half an hour. The inlet before the DOE/ARM impactors was heated to achieve $40 \%$ RH. Additional heating in the reference nephelometer and in a heated tube before the DOE/ARM humidifier brought the sample $\mathrm{RH}$ of the reference nephelometer on average to $25.7 \%$ (standard deviation: $\pm 4.5 \% \mathrm{RH}$ ) prior to humidification in the DOE/ARM system.

Every hour the RH measurement cycle started with a zero measurement (particle free air to correct for the scattering contribution from air molecules). Then the $\mathrm{RH}$ was raised in both humidified instruments stepwise to $80-85 \%$ within $30 \mathrm{~min}$, and was then decreased back to RH values of about $40 \%$ during the second half an hour. The RH in the PSI humidifier always stayed above $80 \%$ while the RH in the PSI nephelometer was decreased to $55 \%$ under these dehydration 

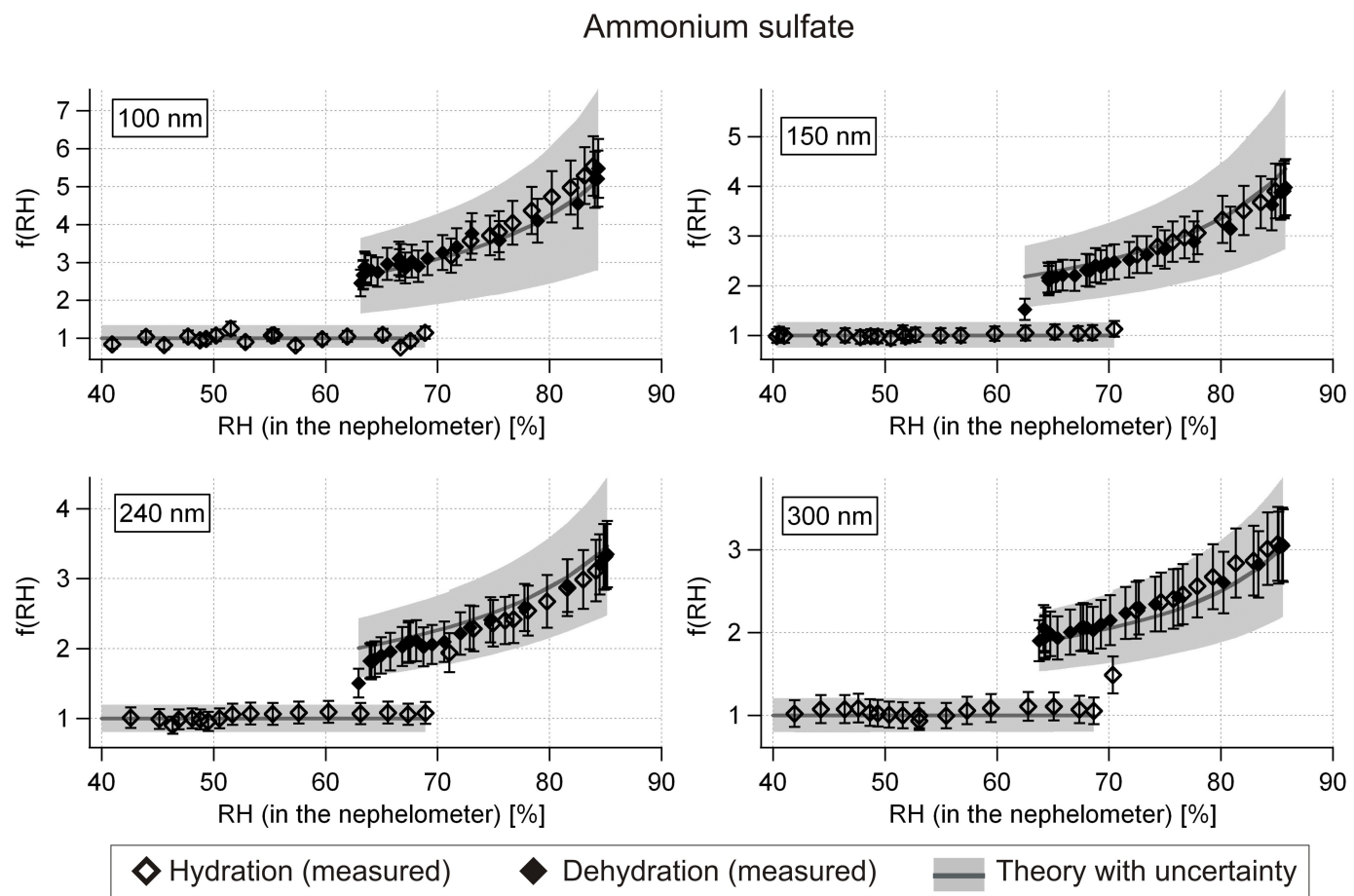

Fig. 3. $f(\mathrm{RH})$ vs. $\mathrm{RH}$ in the nephelometer of ammonium sulfate particles with a dry diameter of $100,150,240$, and $300 \mathrm{~nm}$. The grey lines represent the predicted $f(\mathrm{RH})$ with corresponding uncertainties. Black open diamonds show the measured $f(\mathrm{RH})$ of hydrating aerosols, while black closed diamonds represent dehydrating aerosols. The phase transition at deliquescence occurred at $\mathrm{RH}=79.9 \%$ at the most humid location in the system $\left(\mathrm{RH}_{3}\right)$.

conditions. If the aerosol shows a hysteresis behavior both branches of the hysteresis curve can be measured with this set-up provided that the aerosol had gone below the ERH point in the DOE/ARM reference nephelometer.

To calculate the $f(\mathrm{RH})$ the $\sigma_{\mathrm{sp}}$ from the reference nephelometer of DOE/ARM were taken. Because the DOE/ARM instrument changed between $\mathrm{PM}_{10}$ and $\mathrm{PM}_{1}$ every half hour and the PSI instrument did not, a comparison between the two instruments was only possible for half of the measured time. For comparing the two humidified nephelometers at $80 \% \mathrm{RH}$ values of $f(\mathrm{RH})$ between 78 and $82 \% \mathrm{RH}$ were taken.

\section{Results and discussion}

In this section we first present the validation of the PSI humidified nephelometer with a defined laboratory aerosol. Measurements are compared to model predictions. In the second part we present field results where the new instrument (PSI humidified nephelometer) is compared with the DOE/ARM humidified nephelometer. Even though the nephelometer measures at three different wavelengths $(\lambda=450,550$ and $700 \mathrm{~nm})$ all results are shown at $550 \mathrm{~nm}$ wavelength. For the other wavelengths we obtained similar results.

\subsection{Laboratory measurements}

\subsubsection{Measurements with ammonium sulfate}

By using $\sigma_{\mathrm{sp}}$ at different $\mathrm{RH}$ values we calculated $f(\mathrm{RH})$ with Eq. (1) for all humidities and sizes. Figure 3 shows the obtained $f(\mathrm{RH})$ versus the $\mathrm{RH}$ in the nephelometer for the four measured quasi monodisperse sizes (with singly charged particles with diameters between 100 and $300 \mathrm{~nm}$ ). Open diamonds represent $f(\mathrm{RH})$ while the aerosol was hydrated, whereas the closed diamonds show $f(\mathrm{RH})$ during the dehydration stage of the measurement cycle. The black error bars indicate the measurement uncertainty of $\pm 10 \%$ of $\sigma_{\mathrm{sp}}$ (Anderson et al., 1996). The grey lines show predicted values with corresponding uncertainties. The uncertainties are calculated as described in Sect. 2.2.

As explained in Sect. 2.1, the highest RH in the system is encountered upstream of the dryer (at $\mathrm{RH}_{3}$ in Fig. 1). As a consequence, ammonium sulfate deliquesces if RH exceeds $79.9 \%$ RH (at $298 \mathrm{~K}$ (Tang and Munkelwitz, 1993)) at this point, even if the RH further downstream in the nephelometer is lower. Therefore, in all the humidograms in Fig. 3 the phase transition appears at the lower sample RH of $\sim 72 \%$ of the nephelometer. Below $72 \%$ RH points on the upper branch of the hysteresis curve only occur for dehydration 


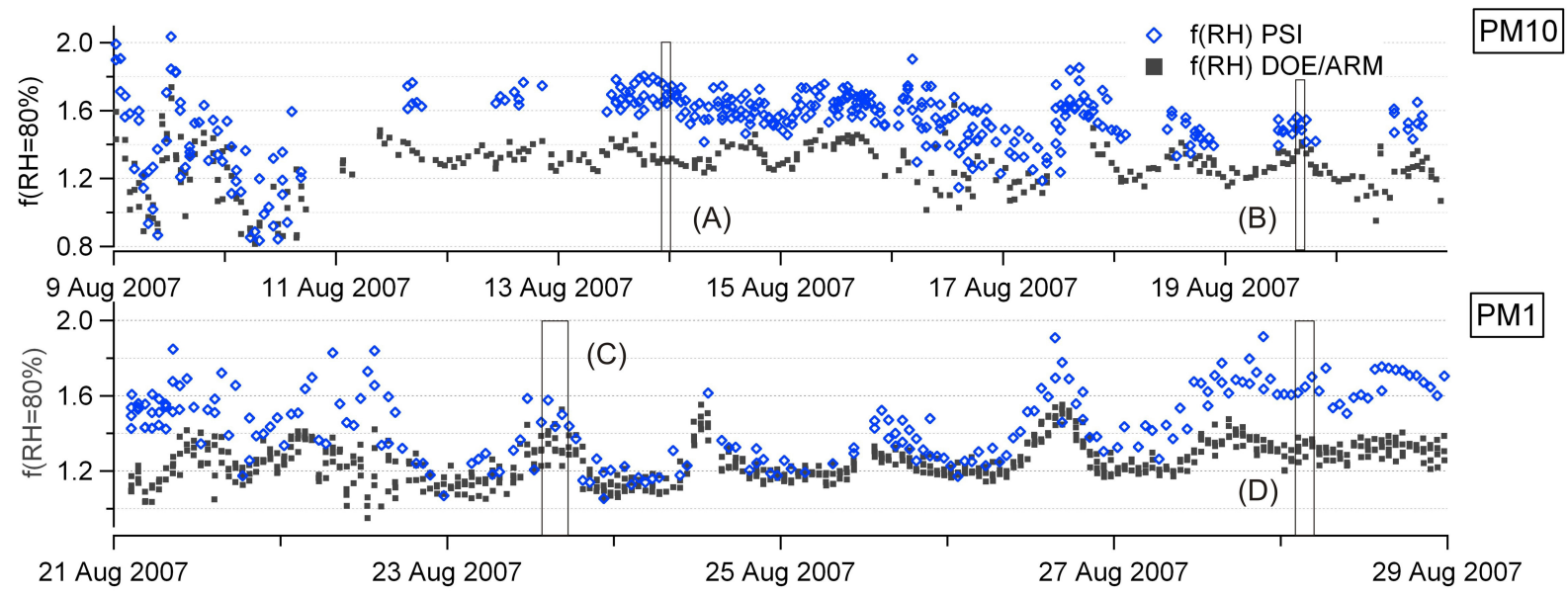

Fig. 4. $\mathrm{PM}_{10}$ and $\mathrm{PM}_{1} f(\mathrm{RH}=80 \%)$ measured with the humidified nephelometer of DOE/ARM and PSI. Time resolution is 1 min. (A) to (D) indicate the periods when the humidograms presented in Fig. 5 were measured.

conditions. The lowest $\mathrm{RH}$ reached while drying was $\sim 62 \%$ $\mathrm{RH}$, therefore we could not detect the ERH. The measurements agree with the model prediction within their rather large uncertainties.

For $f(\mathrm{RH})$, a very good agreement with model predictions is found at all measured sizes (difference between model prediction and measurement between 4.4 and 6.9\%). The $f(\mathrm{RH})$ agrees much better with the model predictions than the $\sigma_{\mathrm{sp}} / N$ (difference between -16.3 and 29.0\%) (Fig. A 2 in the Appendix) because systematic errors mainly in the number size distribution are compensated. $f(\mathrm{RH})$ is largest for the $100-\mathrm{nm}$ particles $(4.5$ at $80 \% \mathrm{RH})$ and smallest for the largest selected particles $(2.5$ at $80 \% \mathrm{RH})$.

\subsubsection{Measurements with sodium cholride}

Similar measurements with quasi monodisperse $\mathrm{NaCl}$ particles were performed. $\sigma_{\mathrm{sp}} / N$ of $\mathrm{NaCl}$ at dry conditions is comparable to that of ammonium sulfate (see Figs. A2 and A3 in the Appendix), but differs for aqueous particles of the two salts. The $f(\mathrm{RH})$ of $\mathrm{NaCl}$ is larger than of ammonium sulfate (Fig. A4 and 3). Due to a higher hygroscopicity the scattering of the $100-\mathrm{nm}$ particles at $80 \% \mathrm{RH}$ was enhanced by a factor of 15 compared to 4.5 for ammonium sulfate. Predicted and measured $f(\mathrm{RH})$ of $\mathrm{NaCl}$ agree within the uncertainty for all selected sizes.

\subsection{Field measurements}

A field comparison between the PSI and the DOE/ARM humidified nephelometers was performed in the Black Forest (Germany) from 9 to 31 August 2007. DOE/ARM measured $\sigma_{\mathrm{sp}}$ in a reference (low RH) and humidified nephelometer as described above. Both humidified nephelometers detected lower $\sigma_{\mathrm{sp}}$ than the reference nephelometer when they were measuring below $40 \% \mathrm{RH}$. This difference was attributed to sampling losses and was empirically corrected by multiplying $\sigma_{\mathrm{sp}}$ of the humidified nephelometers by 1.058 (DOE/ARM, PM 10 ), $1.066\left(\mathrm{DOE} / \mathrm{ARM}, \mathrm{PM}_{1}\right)$ and 1.031 (PSI, both size cuts).

Figure 4 shows the $f(\mathrm{RH})$ at $80 \% \mathrm{RH}$ of both instruments, which includes all $f(\mathrm{RH})$ values at RH between 78 and $82 \%$. In the beginning of the comparison (9-20 August), the PSI humidified nephelometer measured $\sigma_{\mathrm{sp}}$ for the $\mathrm{PM}_{10}$ size range, and from 21 to 29 August for $\mathrm{PM}_{1}$. The $f(\mathrm{RH}=80 \%)$ obtained by the PSI humidified nephelometer was on average $21 \%\left(\mathrm{PM}_{10}\right)$ and $16 \%\left(\mathrm{PM}_{1}\right)$ higher than the one of DOE/ARM, which will be discussed below. $f(\mathrm{RH})$ values at $80 \% \mathrm{RH}$ ranged from 1.2 to 1.8 (PSI) and 1.1 to 1.5 (DOE/ARM) respectively.

The most likely explanation for the difference in the $f(\mathrm{RH})$ of the two instruments is that they occasionally probe the two different branches of the hysteresis curve, since the RH history in the two instruments is not the same. To illustrate this hypothesis, we plotted four example humidograms (with 3-4 RH cycles each) in Fig. 5, showing $\sigma_{\text {sp }}$ vs. the RH in the nephelometers. Humidograms A and B are from the time period where the PSI humidified nephelometer measured $\mathrm{PM}_{10}$, whereas humidograms $\mathrm{C}$ and D illustrate periods, when the size cut was $\mathrm{PM}_{1}$. The black curves display $\sigma_{\mathrm{sp}}$ of the DOE/ARM humidified nephelometer and the colored curves show $\sigma_{\text {sp }}$ of the PSI humidified nephelometer. The color of these curves represents the highest RH in the PSI system (at $\mathrm{RH}_{3}$ ). The instruments agree within $15 \%$ for all RH in humidograms B and C (see boxes in Fig. 4). No distinct deliquescence is observed. For these selected time periods the $f(\mathrm{RH}=80 \%)$ of the two instruments also agree within $11 \%\left(\mathrm{PM}_{1}\right)$ or $10 \%\left(\mathrm{PM}_{10}\right)$ (see Fig. 4). Humidograms $\mathrm{A}$ and $\mathrm{D}$ were measured when the $f(\mathrm{RH}=80 \%)$ of the two 

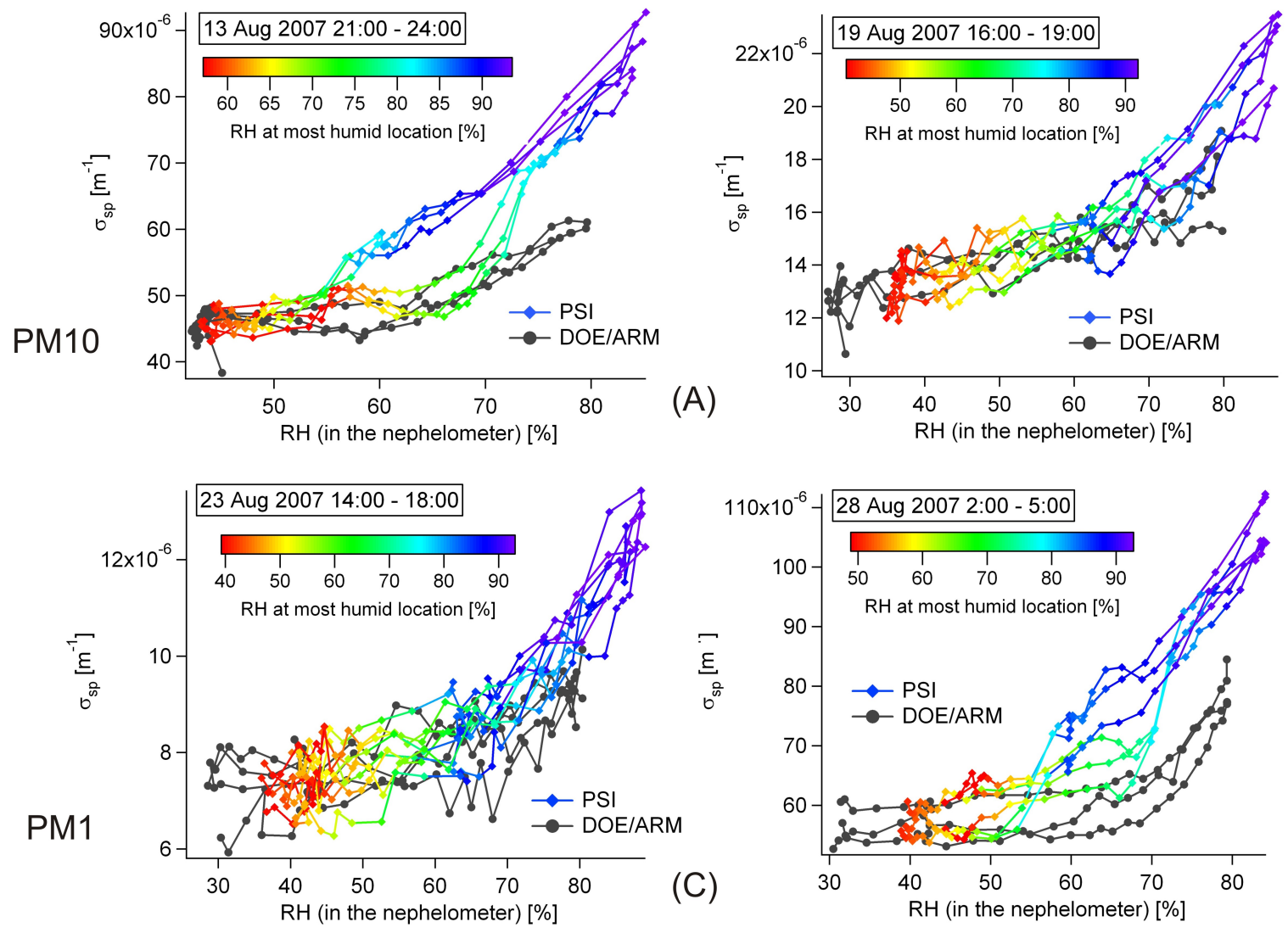

Fig. 5. Humidograms of the scattering coefficient vs. RH in the nephelometer at four selected time periods for $\mathrm{PM}_{10}(\mathbf{A}$ and $\mathbf{B})$ and $P M_{1}(\mathbf{C}$ and D). The black curves are measured by the DOE/ARM humidified nephelometer. The colored curves show $\sigma_{\mathrm{sp}}$ from the PSI humidified nephelometer, where the color represents the $\mathrm{RH}$ at the most humid location in its system $\left(\mathrm{RH}_{3}\right)$. Hysteresis behavior is seen in humidograms (A) and (D).

humidified nephelometers differed a lot (DOE/ARM: 1.25, PSI: 1.6). During this time $\sigma_{\mathrm{sp}}$ showed a distinct hysteresis behavior, which is seen by the PSI humidified nephelometer (see Fig. 5). The $\sigma_{\mathrm{sp}}$ values of the hydration branches of the PSI humidified nephelometer in humidogram A agree within $10 \%$ with the DOE/ARM $\sigma_{\mathrm{sp}}$ values up to about 65 to $70 \% \mathrm{RH}$ in the nephelometers; those in humidogram D agree within $10 \%$ up to $50-55 \%$ RH. When the RH in the PSI humidified nephelometer is $70 \%$, the highest $\mathrm{RH}$ reached in its system is about $78-80 \% \mathrm{RH}$. With increasing $\mathrm{RH} \sigma_{\mathrm{sp}}$ in the PSI humidified nephelometer increases rapidly, most probably because the DRH level was exceeded. At the same RH the DOE/ARM humidified nephelometer measures much lower $\sigma_{\mathrm{sp}}$ since the aerosol particles did not experience the $\mathrm{RH}$ at which they would deliquesce. When we compare $\sigma_{\mathrm{sp}}$ of DOE/ARM at $80 \% \mathrm{RH}$ to $\sigma_{\mathrm{sp}}$ of PSI at $80 \% \mathrm{RH}$ of the most humid location they agree within $7 \%$. As long as the highest RH in the PSI humidified nephelometer stays above $80 \%$, the particles are liquid and therefore scatter more light than they do at the same RH in the DOE/ARM instrument.
Other hypotheses for the observed differences are evaporation of semi-volatile substances in the tubes or in the humidifier, due to different residence times and temperatures; alternatively, aerosol particles in the DOE/ARM system might not experience sufficient residence time to equilibrate in the elevated humidity. The latter artifact would not always be apparent because it is expected to be dependent on the particle chemical composition. It has been shown that some organic/inorganic aerosol mixtures show mass transfer limitations of water and may require residence times of a few seconds for equilibration at $85 \% \mathrm{RH}$ (contrary to pure inorganic salts which equilibrate within timescales of $<1 \mathrm{~s}$ ) (Sjogren et al., 2007; Duplissy et al., 2009). Measurements of the aerosol composition, including organic aerosol speciation, would be needed to evaluate these hypotheses; unfortunately, such measurements were not available during the comparison period. 


\section{Conclusions}

We built a humidification system for a nephelometer that allows for the measurement of $\sigma_{\mathrm{sp}}$ at a defined humidity in the range of 40 to $90 \% \mathrm{RH}$. The system is able to measure the hygroscopic aerosol behavior and hysteresis effects. Monodisperse ammonium sulfate and sodium chloride particles were measured at four different dry particle sizes. Agreement between measurement and prediction based on Mie theory was found for both $\sigma_{\mathrm{sp}}$ and $f(\mathrm{RH})$ within the range of uncertainty.

The intercomparison between the two humidified nephelometers (PSI and DOE/ARM) indicated that the DOE/ARM instrument measured predominately the $f(\mathrm{RH})$ that is representative of the lower hydration curve. The PSI humidified nephelometer measured the $f(\mathrm{RH})$ of the hydration and dehydration branch of the hysteresis curve. When both instruments measured aerosol that exhibits no distinct deliquescence they agreed well. Moreover the measurement of the dehydration branch provides additional information which is important since aged atmospheric aerosols are usually in this deliquesced phase (Weingartner et al., 2002). Carrico et al. (2003) found that ambient aerosol was typically on the upper branch of the hysteresis curve for marine and polluted air masses and on the lower branch for dust-dominated aerosols. Measurements of that type are needed at many different locations over the world in order to reduce the large uncertainties in the radiative forcing due to the direct aerosol effect. In order to decide if the ambient aerosol is actually metastable, another nephelometer measuring at ambient conditions would be needed. Alternatively, this could also be done in a single instrument, by heating and cooling the aerosol and then detecting if there is a difference in the scattering before and after heating, as shown by Larson et al. (1982) and Rood et al. (1987).

\section{Appendix A}

\section{Additional information}

Figure A1a sketches the measured $T$ and RH development for humidification only (hydration mode) and Fig. A1b shows the progression of $\mathrm{RH}$ and $T$ if the dryer is on (dehydration mode).

Figure A2 shows the RH dependence of the measured scattering coefficient normalized by the number concentration $\left(\sigma_{\mathrm{sp}} / N\right)$ for quasi monodisperse ammonium sulfate particles (singly charged particles with diameters between 100 and $300 \mathrm{~nm}$ ). For perfectly monodisperse aerosols this value equals the scattering cross-section per particle. Note that this value is strongly size dependent and therefore biased by the influence of the larger, multiply charged particles. This is taken into account in the Mie calculation of the $\sigma_{\mathrm{sp}} / N$ values (grey lines). Open diamonds represent $\sigma_{\mathrm{sp}} / N$ while the aerosol was hydrated, whereas the closed diamonds show

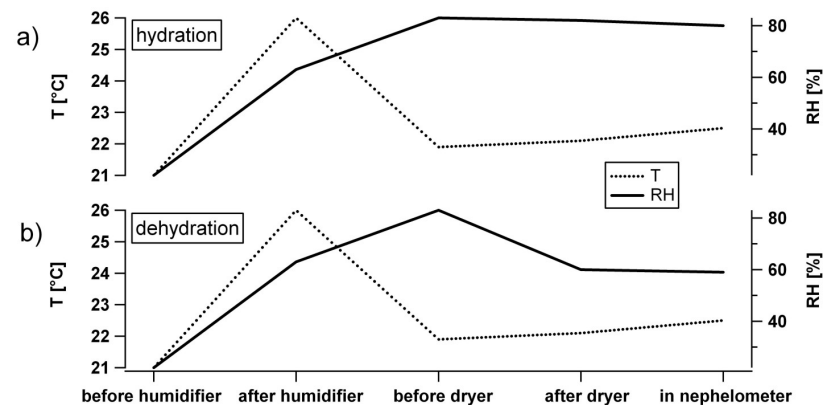

Fig. A1. Example for the evolution of RH and $T$ through the humidified nephelometer with dryer off (a) and dryer on (b). X-axis refers to $T$ and RH measurement points in Fig. 1.

$\sigma_{\mathrm{sp}} / N$ during the dehydration stage of the measurement cycle. The black error bars indicate the measurement uncertainty of $\pm 10 \%$ of $\sigma_{\mathrm{sp}}$. The grey line shows predicted values with corresponding uncertainties. The dry $\sigma_{\mathrm{sp}}$ varied within typical ambient values, i.e. from $2 \times 10^{-6} \mathrm{~m}^{-1}$ of the 100 $\mathrm{nm}$ particles to $4 \times 10^{-5} \mathrm{~m}^{-1}$ of the $300-\mathrm{nm}$ particles. The corresponding number concentrations were $1400 \mathrm{~cm}^{-3}$ and $350 \mathrm{~cm}^{-3}$, respectively. This resulted e.g. in $\sim 130$ times higher $\sigma_{\mathrm{sp}} / N$ for the 300-nm particles compared to the 100$\mathrm{nm}$ particles. The highest $\mathrm{RH}$ in the system is encountered upstream of the dryer (at $\mathrm{T}_{3}, \mathrm{RH}_{3}$ in Fig. 1). As a consequence, ammonium sulfate deliquesces if RH exceeds $79.9 \%$ $\mathrm{RH}$ (at $298 \mathrm{~K}$ ) at this point, even if the RH further downstream in the nephelometer is lower. Therefore, in all the humidograms in Fig. A2 the phase transition appears at the lower sample RH of about $72 \%$ of the nephelometer. Below $72 \% \mathrm{RH}$, points on the upper branch of the hysteresis curve only occur for dehydration conditions. The lowest RH reached while drying was $62 \% \mathrm{RH}$, therefore we could not detect the ERH. The measurements agree with the model prediction within their rather large uncertainties (the difference of of $\sigma_{\mathrm{sp}} / N$ between model prediction and measurement is between -16.3 and $29.0 \%$ ).

Figure A3 shows the measured and predicted scattering coefficient normalized by the number concentration $\left(\sigma_{\mathrm{sp}} / N\right)$ for monodisperse sodium chloride particles with the same dry diameter as for the ammonium sulfate measurement (Fig. A2 and Fig. 3). As explained above, the highest RH in the system is encountered upstream of the dryer (at $\mathrm{T}_{3}, \mathrm{RH}_{3}$ in Fig. 1). As a consequence, sodium chloride deliquesces if $75.3 \% \mathrm{RH}$ (at $298 \mathrm{~K}$ ), is exceeded at this point and not in the nephelometer. Therefore, in all the humidograms in Figs. A3 and A4 the phase transition appears at the lower sample RH of about $70 \%$ of the nephelometer. The difference between of of $\sigma_{\mathrm{sp}} / N$ model prediction and measurement ranges between -16.6 and $25.7 \%$. Figure A4 shows the corresponding $f(\mathrm{RH})$ measurement for sodium chloride particles (the difference of $f(\mathrm{RH})$ between model prediction and measurement is between -3.7 and $8.2 \%$ ). 

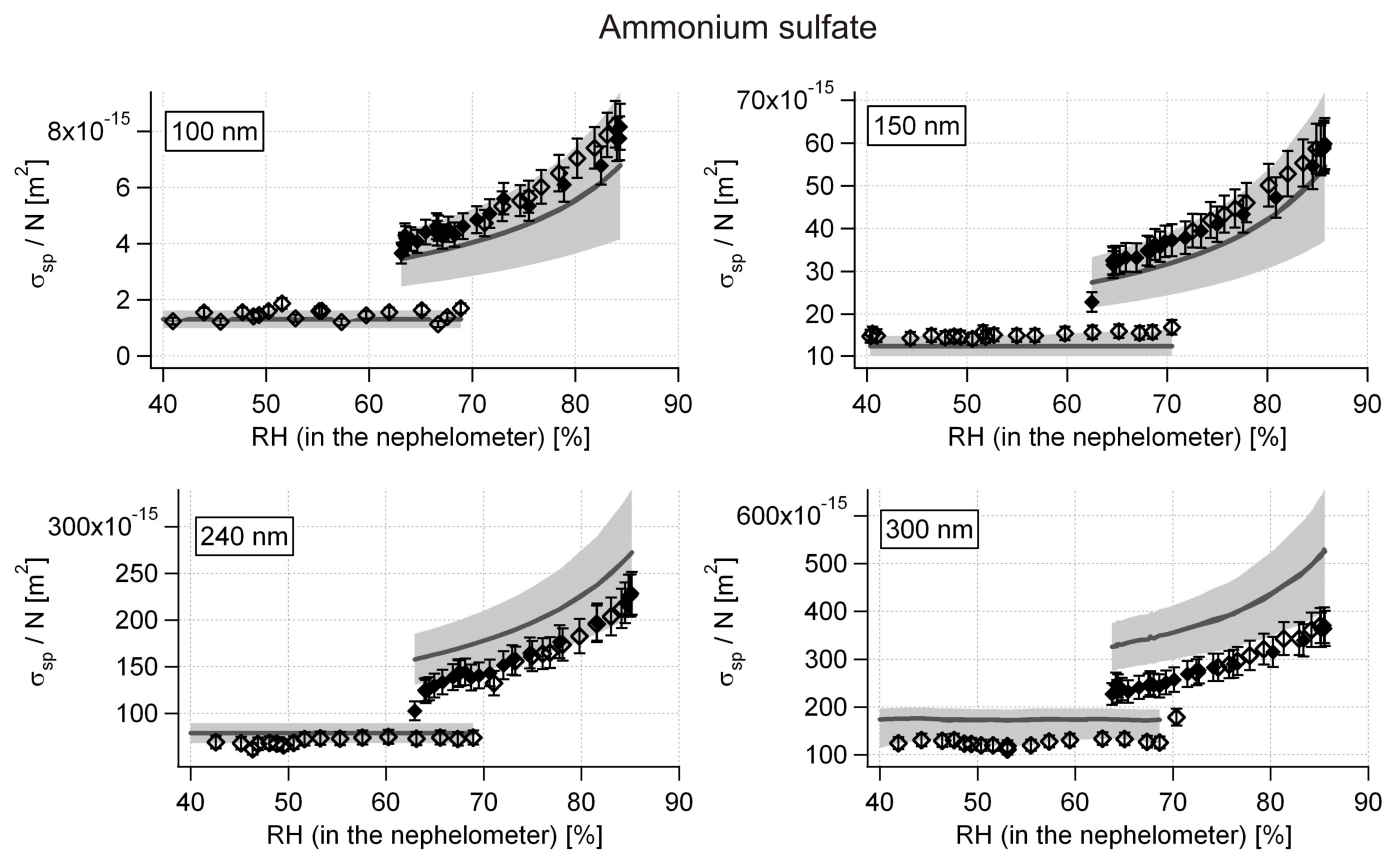

Hydration (measured)

Dehydration (measured)

Theory with uncertainty

Fig. A2. Scattering coefficient normalized by the number concentration vs. RH in the nephelometer of quasi monodisperse ammonium sulfate particles with dry diameters between 100 and $300 \mathrm{~nm}$. The grey lines represent the predicted values, with their corresponding uncertainties. The black open diamonds show the measured $\sigma_{\mathrm{sp}} / N$ while hydrating, whereas the black closed diamonds illustrate the corresponding dehydration values. The black error bars illustrate the measurement uncertainty of the nephelometer.

\section{Sodium chloride}
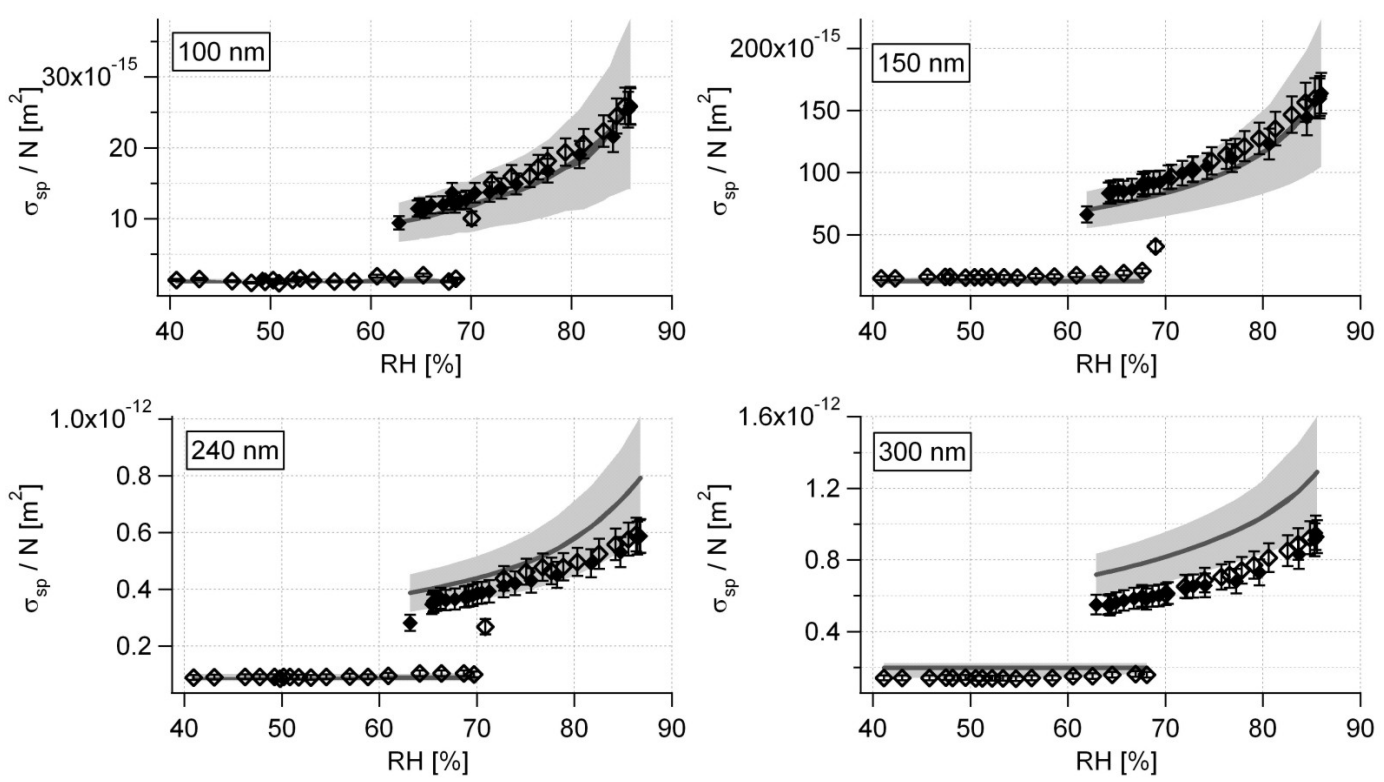

$\diamond$ Hydration (measured) $\diamond$ Dehydration (measured) Theory with uncertainty

Fig. A3. Scattering coefficient normalized by the number concentration vs. RH in the nephelometer of quasi monodisperse sodium chloride particles with diameters between 100 and $300 \mathrm{~nm}$. The grey lines represent the predicted values, with their corresponding uncertainties. The black open diamonds show the measured $\sigma_{\mathrm{sp}} / N$ while hydrating, whereas the black closed diamonds illustrate the corresponding dehydration values. The black error bars illustrate the measurement uncertainty of the nephelometer. 

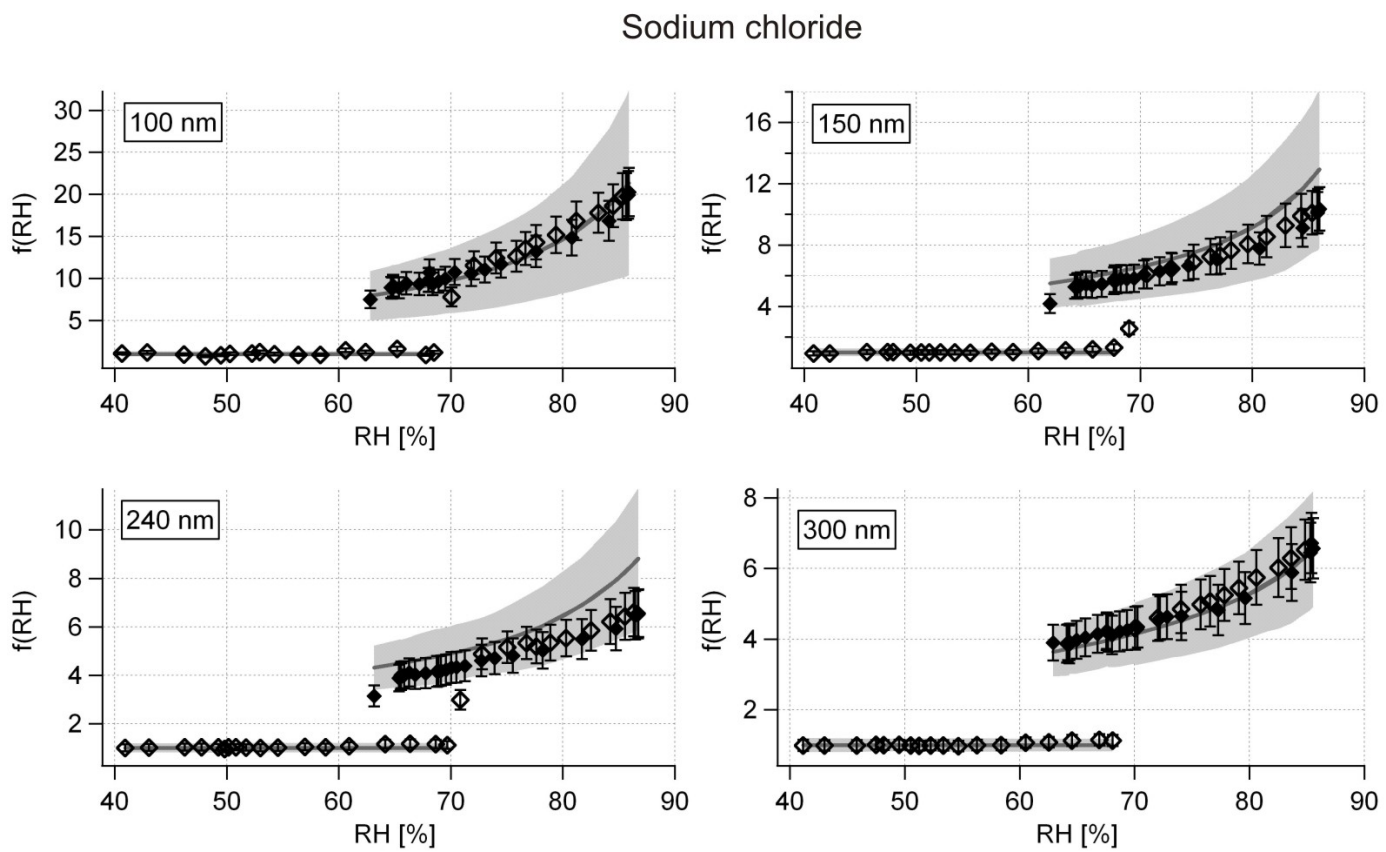

Hydration (measured)

Dehydration (measured)

Theory with uncertainty

Fig. A4. $f(\mathrm{RH})$ vs. $\mathrm{RH}$ of sodium chloride particles with a diameter of 100, 150, 240, and $300 \mathrm{~nm}$. The grey lines represent the predicted $f(\mathrm{RH})$ with corresponding uncertainties. Black open diamonds show the measured $f(\mathrm{RH})$ of hydrating aerosols, while black closed diamonds represent dehydrating aerosols.
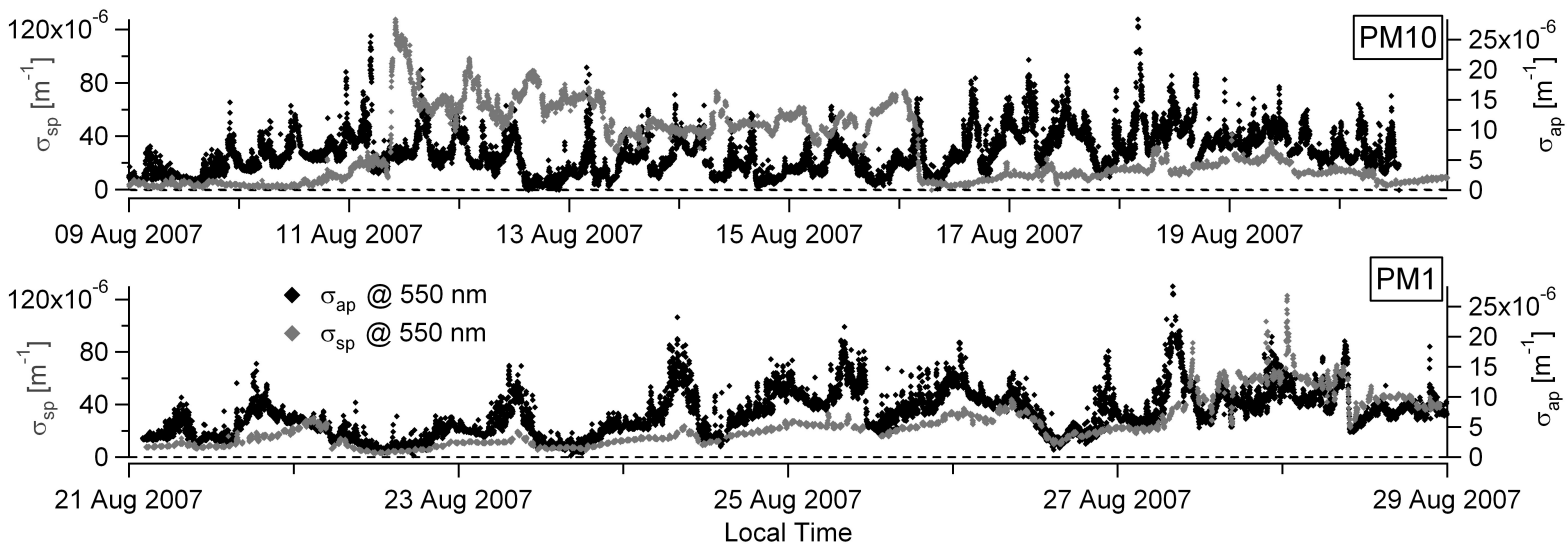

Fig. A5. $\mathrm{PM}_{10}$ and $\mathrm{PM}_{1}$ scattering $\left(\sigma_{\mathrm{sp}}\right)$ and absorption coefficients $\left(\sigma_{\mathrm{ap}}\right)$ measured by DOE/ARM with a nephelometer and a PSAP $($ particle soot absorption photometer) at $550 \mathrm{~nm}$ wavelength. Time resolution is $1 \mathrm{~min}$.

DOE/ARM measured absorption coefficients $\left(\sigma_{\text {ap }}\right)$ with a PSAP (particle soot absorption photometer) and light scattering coefficients $\left(\sigma_{\mathrm{sp}}\right)$ with a nephelometer. Figure A5 shows these values from 9 to 20 August for $\mathrm{PM}_{10}$ and from 21 to 29 August for $\mathrm{PM}_{1}$. The $\mathrm{PM}_{1}$ scattering and absorption data exhibited a clear diurnal pattern, with highest values in the late morning and in the night. The increase in the morning is probably due to higher particle concentrations from local emissions as well as low vertical mixing, as the number concentration (not shown) exhibits the same pattern. The following midday decrease is likely due to dilution through enhanced vertical mixing. This vertical mixing (with aged air from the residual layer) is also reflected in an enhanced $f(\mathrm{RH})$ (see Fig. 4), as particles with more secondary material are more hygroscopic, grow more and consequently have a higher $f(\mathrm{RH})$. 
Acknowledgements. This work was supported by the EC projects EUSAAR (European Supersites for Atmospheric Aerosol Research) and GEOMON (Global Earth Observation and Monitoring). Data were obtained from the Atmospheric Radiation Measurement (ARM) Program sponsored by the US Department of Energy, Office of Science, Office of Biological and Environmental Research, Environmental Sciences Division. We thank Martin Gysel for valuable discussions.

Edited by: A. Wiedensohler

\section{References}

Anderson, T. L., Covert, D. S., Marshall, S. F., Laucks, M. L., Charlson, R. J., Waggoner, A. P., Ogren, J. A., Caldow, R., Holm, R. L., Quant, F. R., Sem, G. J., Wiedensohler, A., Ahlquist, N. A., and Bates, T. S.: Performance characteristics of a high-sensitivity, three-wavelength, total scatter/backscatter nephelometer, J. Atmos. Oceanic Technol., 13, 967-986, 1996.

Anderson, T. L. and Ogren, J. A.: Determining aerosol radiative properties using the TSI 3563 integrating nephelometer, Aerosol Sci. Tech., 29, 57-69, 1998.

Bergin, M. H., Ogren, J. A., Schwartz, S. E., and McInnes, L. M.: Evaporation of ammonium nitrate aerosol in a heated nephelometer: Implications for field measurements, Environ. Sci. Technol., 31, 2878-2883, 1997.

Bohren, C. and Huffmann, D.: Absorption and Scattering of Light by Small Particles, Wiley-VCH, New York, USA, 2004.

Boucher, O. and Anderson, T. L.: General circulation model assessment of the sensitivity of direct climate forcing by anthropogenic sulfate aerosols to aerosol size and chemistry, J. Geophys. Res., 100, 26177-126134, 1995.

Carrico, C. M., Rood, M. J., and Ogren, J. A.: Aerosol light scattering properties at Cape Grim, Tasmania, during the First Aerosol Characterization Experiment (ACE 1), J. Geophys. Res., 103, 16565-16574, 1998.

Carrico, C. M., Kus, P., Rood, M. J., Quinn, P. K., and Bates, T. S.: Mixtures of pollution, dust, sea salt, and volcanic aerosol during ACE-Asia: Radiative properties as a function of relative humidity, J. Geophys. Res., 108(D23), 8650, doi:10.1029/2003JD003405, 2003.

Chamaillard, K., Kleefeld, C., Jennings, S. G., Ceburnis, D., and O'Dowd, C. D.: Light scattering properties of sea-salt aerosol particles inferred from modeling studies and ground-based measurements, J. Quant. Spectrosc. Radiat. Transfer, 101, 498-511, 2006.

Charlson, R. J., Schwartz, S. E., Hales, J. M., Cess, R. D., Coakley, J. A., Jr., Hansen, J. E., and Hofmann, D. J.: Climate forcing by anthropogenic aerosols, Science, 255, 423-430, 1992.

Covert, D. S., Charlson, R. J., and Ahlquist, N. C.: A study of the relationship of chemical composition and humidity to the light scattering by aerosols, J. Appl. Meteorol., 11, 968-976, 1972.

Duplissy, J., Gysel, M., Sjogren, S., Meyer, N., Good, N., Kammermann, L., Michaud, V., Weigel, R., Martins dos Santos, S., Gruening, C., Villani, P., Laj, P., Sellegri, K., Metzger, A., McFiggans, G. B., Wehrle, G., Richter, R., Dommen, J., Ristovski, Z., Baltensperger, U., and Weingartner, E.: Intercomparison study of six HTDMAs: results and recommendations, Atmos. Meas.
Tech., 2, 363-378, 2009, http://www.atmos-meas-tech.net/2/363/2009/.

Eldering, A., Ogren, J. A., Chowdhury, Z., Hughes, L. S., and Cass, G. R.: Aerosol optical properties during INDOEX based on measured aerosol particle size and composition, J. Geophys. Res., 107(D22), 8001, doi:10.1029/2001JD001572, 2002.

Fierz-Schmidhauser, R., Zieger, P., Gysel, M., Kammermann, L., DeCarlo, P. F., Baltensperger, U., and Weingartner, E.: Measured and predicted aerosol light scattering enhancement factors at the high alpine site Jungfraujoch, Atmos. Chem. Phys. Discuss., 9, 20063-20101, 2009,

http://www.atmos-chem-phys-discuss.net/9/20063/2009/.

Haywood, J. M., Bush, M., Osborne, S. R., Abel, S. J., Claxton, B., Macpherson, B., Harrison, M., Crosier, J., and Coe, H.: Prediction of visibility and aerosol within the operational Met Office Unified Model. II: Validation of model performance using observational data, Q. J. Roy. Meteor. Soc., 134, 1817-1832, 2008.

IPCC: Climate Change 2007 - The Physical Science Basis, edited by: Solomon, S., Cambridge Univ. Press, New York, 2007.

Kim, J., Yoon, S.-C., Jefferson, A., and Kim, S.-W.: Aerosol hygroscopic properties during Asian dust, pollution, and biomass burning episodes at Gosan, Korea, in April 2001, Atmos. Environ., 40, 1550-1560, 2006.

Larson, T. V., Ahlquist, N. C., Weiss, R. E., Covert, D. S., and Waggoner, A. P.: Chemical speciation of $\mathrm{H}_{2} \mathrm{SO}_{4}-\left(\mathrm{NH}_{4}\right)_{2} \mathrm{SO}_{4}$ particles using temperature and humidity controlled nephelometry, Atmos. Environ., 16, 1587-1590, 1982.

Nessler, R., Weingartner, E., and Baltensperger, U.: Adaptation of dry nephelometer measurements to ambient conditions at the Jungfraujoch, Environ. Sci. Technol., 39, 2219-2228, 2005.

Orr Jr., C., Hurd, K., and Corbett, W. J.: Aerosol size and relative humidity, J. Coll. Sci. , 13, 472-482, 1958.

Pilinis, C., Pandis, S. N., and Seinfeld, J. H.: Sensitivity of direct climate forcing by atmospheric aerosols to aerosol size and chemistry, J. Geophys. Res., 100, 18739-18754, 1995.

Ramanathan, V., Crutzen, P. J., Kiehl, J. T., and Rosenfeld, D.: Aerosols, climate, and the hydrological cycle, Science, 204, 2119-2124, 2001.

Rood, M. J., Covert, D. S., and Larson, T. V.: Hygroscopic properties of atmospheric aerosol in Riverside, California, Tellus, 39B, 383-397, 1987.

Rood, M. J., Shaw, M. A., Larson, T. V., and Covert, D. S.: Ubiquitous nature of ambient metastable aerosol, Nature, 337, 537-539, 1989.

Schwartz, S. E.: The whitehouse effect - shortwave radiative forcing of climate by anthropogenic aerosols: an overview, J. Aerosol Sci., 27, 359-382, 1996.

Sheridan, P. J., Delene, D. J., and Ogren, J. A.: Four years of continuous surface aerosol measurements from the Department of Energy's Atmospheric Radiation Program Southern Great Plains Cloud and Radiation Testbed site, J. Geophys. Res., 106, 2073520747, 2001.

Sjogren, S., Gysel, M., Weingartner, E., Baltensperger, U., Cubison, M. J., Coe, H., Zardini, A. A., Marcolli, C., Krieger, U. K., and Peter, T.: Hygroscopic growth and water uptake kinetics of twophase aerosol particles consisting of ammonium sulfate, adipic and humic acid mixtures, J. Aerosol Sci., 38, 157-171, 2007. 
Sloane, C. S.: Optical properties of aerosols of mixed composition, Atmos. Environ., 18, 871-878, 1984.

Tang, I. N., Wong, W. T., and Munkelwitz, H. R.: The relative importance of atmospheric sulfates and nitrates in visibility reduction, Atmos. Environ., 15, 2463-2471, 1981.

Tang, I. N. and Munkelwitz, H. R.: Composition and temperature dependence of the deliquescence properties of hygroscopic aerosols, Atmos. Environ., 27A, 467-473, 1993.

ten Brink, H. M., Khlystov, A., Kos, G. P. A., Tuch, T., Roth, C., and Kreyling, W.: A high-flow humidograph for testing the water uptake by ambient aerosol, Atmos. Environ., 34, 4291-4300, 2000.

Topping, D. O., McFiggans, G. B., and Coe, H.: A curved multicomponent aerosol hygroscopicity model framework: Part 1 - Inorganic compounds, Atmos. Chem. Phys., 5, 1205-1222, 2005, http://www.atmos-chem-phys.net/5/1205/2005/.

Wang, W., Rood, M. J., Carrico, C. M., Covert, D. S., Quinn, P. K., and Bates, T. S.: Aerosol optical properties along the northeast coast of North America during the New England Air Quality Study - Intercontinental Transport and Chemical Transformation 2004 campaign and the influence of aerosol composition, J. Geophys. Res., 112, D10S23, doi:10.1029/2006JD007579, 2007.

Weingartner, E., Gysel, M., and Baltensperger, U.: Hygroscopicity of aerosol particles at low temperatures. 1. New low-temperature H-TDMA instrument: Setup and first applications, Environ. Sci. Technol., 36, 55-62, 2002.
White, W. H. and Roberts, P. T.: On the nature and origins of visibility-reducing aerosols in the Los Angeles air basin, Atmos. Environ., 11, 803-812, 1977.

WMO/GAW: Aerosol Measurement Procedures Guidelines and Recommendations, World Meteorological Organization Global Atmosphere Watch, Geneva, Switzerland, 2003.

Wulfmeyer, V., Behrendt, A., Bauer, H.-S., Kottmeier, C., Corsmeier, U., Blyth, A., Craig, G., Schumann, U., Hagen, M., Crewell, S., Girolamo, P. D., Flamant, C., Miller, M., Montani, A., Mobbs, S., Richard, E., Rotach, M. W., Arpagaus, M., Russchenberg, H., Schlüssel, P., König, M., Gärtner, V., Steinacker, R., Dorninger, M., Turner, D. D., Weckwerth, T., Hense, A., and Simmer, C.: Research Campaign: The Convective and Orographically Induced Precipitation Study, B. Am. Meteorol. Soc., 89, 1477-1486, 2008.

Yan, P., Pan, X. L., Tang, J., Zhou, X. J., Zhang, R. J., and Zeng, L. M.: Hygroscopic growth of aerosol scattering coefficient: A comparative analysis between urban and suburban sites at winter in Beijing, Particuology, 7, 52-60, 2009. 